\title{
WPLYW SZYBKOŚCI UTRATY SŁUPA NA DYNAMICZNĄ ODPOWIEDŹ KONSTRUKCJI ŻELBETOWEJ
}

\begin{abstract}
W konstrukcjach ramowych, nagła utrata słupa spowodowana na przykład eksplozją ładunku wybuchowego czy uderzeniem pojazdu powoduje dynamiczną odpowiedź, która w przypadku niewystarczającej odporności konstrukcji może prowadzić do częściowej lub całkowitej katastrofy. Pojęcie "nagłości" jest nieprecyzyjne i dlatego warto zbadać jak szybkość utraty słupa wpływa na maksymalne przemieszczenie i jak to przemieszczenie odnosi się do przemieszczenia statycznej utraty słupa. W tym celu przeprowadzono symulacje numeryczne odpowiedzi żelbetowego budynku słupowo-belkowego, który wcześniej został poddany eksperymentalnej quasi-statycznej utracie słupów. Symulacje polegają na stopniowym wydłużeniu czasu trwania utraty słupa od zera do wartości, która asymptotycznie zbliża się do odpowiedzi statycznej. Ze względu na różne rozpiętości przęseł, rozważono trzy scenariusze utraty słupa. Stwierdzono, że wpływ szybkości utraty słupa zależy od możliwości przeniesienia obciążeń przez pozostałą część konstrukcji, a to przejawia się w wartościach okresu drgań własnych dla postaci w kierunku pionowym konstrukcji bez danego słupa. Podano także czasy trwania utraty słupa, dla których odpowiedź jest na umownym poziomie 95\% maksymalnej odpowiedzi dynamicznej oraz wartości znormalizowanego czasu w stosunku do odpowiedniego okresu drgań własnych, co może posłużyć jako wskazówka przy dobieraniu kroku czasowego całkowania równań ruchu w obliczeń dynamicznych przy użyciu metody elementów skończonych.
\end{abstract}

Słowa kluczowe: postępująca katastrofa, obciążenie wyjątkowe, modelowanie konstrukcji żelbetowej, współczynnik dynamiczny

\section{Wprowadzenie}

Nagła utrata elementu nośnego, jakim jest słup, belka lub fragment ściany, może prowadzić do zjawiska częściowej lub całkowitej katastrofy postępującej. Przyczyną utraty elementu nośnego konstrukcji może być eksplozja ładunku wybuchowego, wybuch gazu, czy uderzenie pojazdu. Analizowanie szczegóło-

${ }^{1}$ Autor do korespondencji / corresponding author: Seweryn Kokot, Politechnika Opolska, Katedra Mechaniki, Konstrukcji Budowlanych i Inżynierskich, ul. Katowicka 48, 45-061 Opole; tel. 77449 8579; s.kokot@po.opole.pl 
we konkretnego przypadku obciążenia wyjątkowego działającego na daną konstrukcję wymaga dużego nakładu pracy na etapie modelowania konstrukcji i obciążenia, dlatego istotne jest przyjęcie założeń, które pozwolą na uproszczenie całego procesu analizy z zachowaniem żądanego poziomu dokładności rozwiązania.

W ostatnich latach pojawiło się wiele wytycznych i przepisów w dokumentach normowych $[1,2,3]$ dotyczących projektowania nowych obiektów, jak również sprawdzenia i wzmacniania istniejących budynków na możliwość wystąpienia obciążenia wyjątkowego prowadzącego do postępującej katastrofy [4]. Oprócz ogólnych wymagać spełnienia integralności konstrukcji poprzez układ stężeń pionowych i poziomych, bardziej dokładne analizy wymagają przeprowadzenia obliczeń dynamicznych za pomocą metody elementów skończonych z uwzględnieniem nieliniowości materiałowych i geometrycznych.

W wielu dokumentach $[1,2,3]$ zalecana jest analiza dynamiczna modelu konstrukcji ze względu na nagłą utratę słupa lub belki. W konstrukcjach ramowych, nagła utrata słupa wywołuje drgania, które w przypadku niewystarczającej odporności konstrukcji może prowadzić do katastrofy. Pojęcie nagłości jest jednak nieprecyzyjne i dlatego ważne jest zbadać jak czas trwania utraty słupa wpływa na odpowiedź dynamiczną. W tym celu przeprowadzono symulacje numeryczne odpowiedzi żelbetowego budynku słupowo-belkowego, który wcześniej został poddany eksperymentalnej utracie słupów [5].

\section{Opis analizowanej konstrukcji i jej model obliczeniowy}

Badanym obiektem niniejszego artykułu jest żelbetowy budynek o dwóch kondygnacjach, dwóch nawach w kierunku podłużnym i jednej nawie w kierunku poprzecznym.

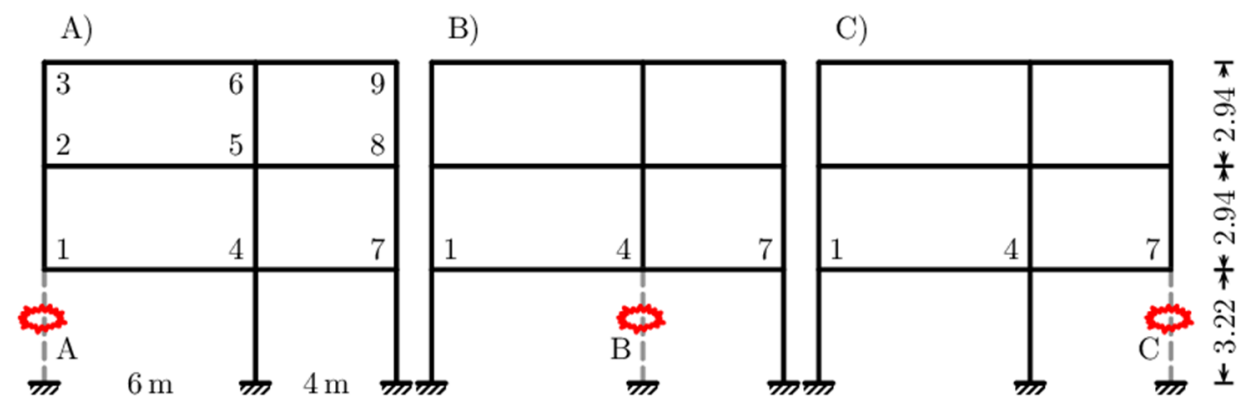

Rys. 1. Wymiary ramy płaskiej i trzy przypadki utraty słupa A, B i C

Fig. 1. Dimensions of the plane frame and three cases of column removal A, B and C

Budynek składa się z dwóch ram płaskich (rys. 1) połączonych belkami poprzecznymi. Rygle ram są szerokości $1 \mathrm{~m}$ i wysokości $0,24 \mathrm{~m}$. Strop posiada 
taką samą wysokość jak rygle (0,20 m grubość stropu i wylewka gr. 0,04 m). Słupy ram są kwadratowe o wymiarach $0,4 \times 0,4 \mathrm{~m}$. Z powodu zredukowanej wysokości rygla, zbrojenie belek jest znaczne po obu stronach, a tylko niektóre pręty zbrojeniowe są zakotwione w słupach. Obiekt ten najpierw został poddany testom sejsmicznym w laboratorium ELSA Wspólnotowego Centrum Badawczego Komisji Europejskiej w Isprze, Włochy [5,6]. Po tych testach można było zaobserwować jedynie nieznaczne zarysowanie w pobliżu połączeń słupów i belek, a następnie budynek ten został przeznaczony do kontrolowanego zniszczenia poprzez wycinanie słupów w sposób quasi-statyczny. Budynek zdołał przenieść utratę obu słupów środkowych ram płaskich, jednak dalsze badania eksperymentalne zostały przerwane ze względów bezpieczeństwa.

W celu analizy różnych możliwości utraty słupa dolnej kondygnacji przyjęto trzy scenariusze A), B) i C), w których osobno utracie podlegają słupy A, B lub C (rys. 1). Model obliczeniowy budynku składa się z 30 ramowych elementów skończonych ( 21 dla belek i 9 dla słupów), przy czym elementy są sformułowane w ujęciu naprężeniowym [7]. Możliwość wystąpienia nieliniowości materiałowej w elementach skończonych uwzględnia się w tzw. punktach Gaussa (5 punktów kontrolnych wzdłuż długości elementu), których przekroje poprzeczne są typu włóknowego (ang. fiber model). Polega to na tym, że przekrój dzieli się na tzw. włókna elementarne, do których przypisane są związki konstytutywne betonu lub stali w zależności od położenia włókna. W pracy tej wykorzystuje się modyfikacje modeli betonu Kenta-Parka [8] i stali Menegotto-Pinto [9], których obwiednie związków naprężenie-odkształcenie pokazane są na rys. 2. Należy dodać, że modele te uwzględniają także degradację sztywności i wytrzymałości przy obciążeniu cyklicznie zmiennym. Ponadto nieliniowość geometryczną przyjęto zgodnie ze sformułowaniem tzw. korotacyjnym [10], które uwzględnia wpływ dużych przemieszczeń w sposób ścisły, w odróżnieniu od tradycyjnego podejścia nieliniowości geometrycznej typu P- $\Delta$.

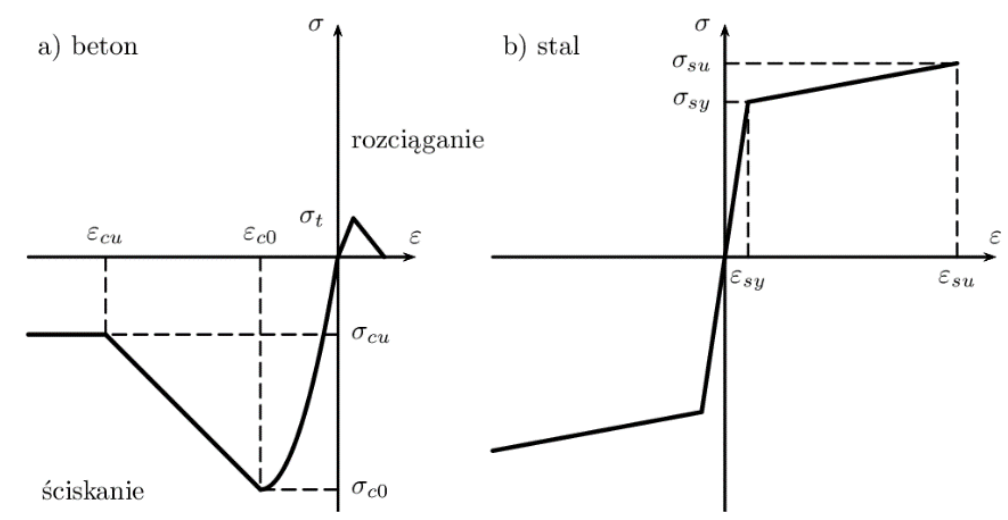

Rys. 2. Obwiednie związków konstytutywnych dla a) betonu i b) stali

Fig. 2. Backbones of constitutive relationships for a) concrete and b) steel 
Podstawowe parametry materiałowe zostały przyjęte na podstawie testów wytrzymałościowych próbek, a ich wartości średnie wynoszą: $\sigma_{\mathrm{c} 0}=37,22 \mathrm{MPa}$, $\varepsilon_{\mathrm{c} 0}=0,002, \sigma_{\mathrm{cu}}=6 \mathrm{MPa}, \varepsilon_{\mathrm{cu}}=0,0035, \sigma_{\mathrm{sy}}=524,6 \mathrm{MPa}, \mathrm{E}_{\mathrm{s}}=200 \mathrm{GPa}, \sigma_{\mathrm{su}}=640 \mathrm{MPa}$, $\varepsilon_{\mathrm{su}}=0,10$.

W tabeli 1 przedstawiono sześć początkowych okresów drgań własnych dla poszczególnych scenariuszy utraty słupa, przy czym pierwsza wartość odnosi się do konstrukcji wyjściowej, a wartość poniżej oznaczona symbolem "*" do konstrukcji po wystąpieniu degradacji sztywności i wytrzymałości w wyniku uplastycznienia w kilku przekrojach. Miarodajne, z punktu widzenia utraty słupa, postacie drgań w kierunku pionowym, dla trzech scenariuszy, pokazane są na rys. 3. Postacie te odnoszą się do okresów $\mathrm{T}_{2} \mathrm{z}$ tabeli 1 , gdyż pierwsze postacie dotyczą przemieszczeń konstrukcji w kierunku poziomym.

Tabela 1. Sześć początkowych okresów drgań własnych dla trzech scenariuszy utraty słupa

Table 1. Six initial natural periods of free vibrations for three column removal scenarios

\begin{tabular}{|c|c|c|c|c|c|c|}
\hline Nr postaci & $\mathbf{T}_{\mathbf{1}}[\mathbf{s}]$ & $\mathbf{T}_{\mathbf{2}}[\mathbf{s}]$ & $\mathbf{T}_{\mathbf{3}}[\mathbf{s}]$ & $\mathbf{T}_{\mathbf{4}}[\mathbf{s}]$ & $\mathbf{T}_{\mathbf{5}}[\mathbf{s}]$ & $\mathbf{T}_{\mathbf{6}}[\mathbf{s}]$ \\
\hline A) & 0,3422 & 0,1883 & 0,0763 & 0,0499 & 0,0488 & 0,0396 \\
A)* & 0,7513 & 0,3777 & 0,1615 & 0,1003 & 0,0949 & 0,0806 \\
\hline B) & 0,2746 & 0,1227 & 0,0772 & 0,0503 & 0,0473 & 0,0412 \\
B)* & 0,5096 & 0,2512 & 0,1447 & 0,0998 & 0,0975 & 0,0827 \\
\hline C) & 0,3469 & 0,1151 & 0,0715 & 0,0506 & 0,0464 & 0,0453 \\
C)* & 0,6229 & 0,2119 & 0,1256 & 0,0828 & 0,0781 & 0,0772 \\
\hline
\end{tabular}
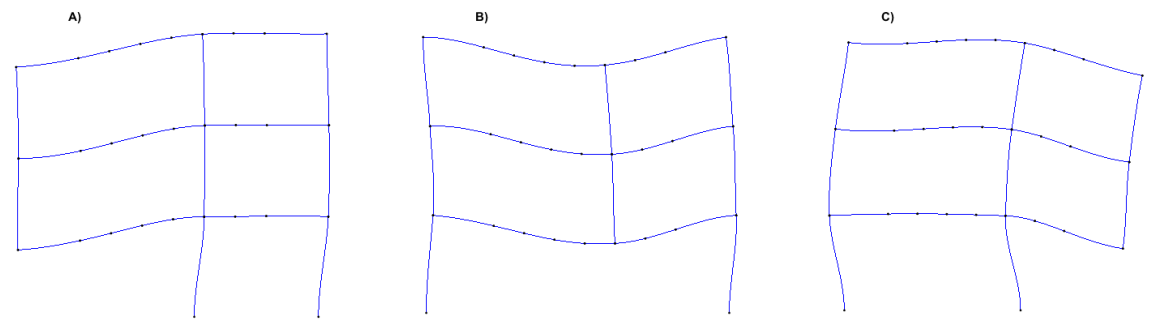

Rys. 3. Postacie drgań własnych w kierunku pionowym dla przypadków utraty słupa A, B i C

Fig. 3. Mode shapes in vertical direction for cases of column removal A, B and C

\section{Procedura obliczeniowa}

Procedura obliczeń numerycznych do celu tego artykułu polega na obliczeniach w pętli, gdzie poszczególne iteracje odnoszą się do stopniowo zwiększanych wartości czasu trwania utraty słupa $t_{r}$. Wewnątrz pętli, dla ustalonej wartości $t_{r}$ obliczenia wykonywane są według następujących kroków: 
- zdefiniowanie modelu MES,

- przyłożenie obciążenia ciężarem własnym i obciążenia bocznego od wiatru,

- odczytanie węzłowych sił przekrojowych słupa w węźle połączenia z pozostałą częścią konstrukcji,

- usunięcie słupa z modelu MES,

- w węźle połączenia z pozostałą częścią konstrukcji, przyłożony jest zestaw sił odpowiadający wcześniej odczytanym siłom w słupie (siły te działają jako stałe w czasie),

- przyłożenie w tym samym węźle zestawu sił przeciwnie skierowanych narastających w czasie $t_{r}$ do pełnej wartości, tak aby symulować utratę słupa,

- wykonanie nieliniowej analizy dynamicznej MES,

- w wyniku obliczeń otrzymuje się przebieg czasowy odpowiedzi, z którego należy wyszukać maksymalną wartość przemieszczenia pionowego w węźle nad usuniętym słupem.

Po wykonaniu pętli obliczeń dla dyskretnych wartości czasu trwania $t_{r}$ usunięcia słupa, wyniki ekstremalnych wartości przemieszczeń pionowych przedstawia się na wykresie.

W symulacjach numerycznych MES wykorzystano metodę Newmarka do rozwiązania równań ruchu z przyjętym krokiem czasowym (np. 0,001 s). Macierz tłumienia Rayleigha obliczono na podstawie 5\% tłumienia dla dwóch pierwszych postaci drgań własnych.

Przedstawioną procedurę, jak i obliczenia można zaimplementować w wielu pakietach obliczeń MES z modułem obliczeń dynamicznych, jednak ze względu na wielokrotne powtarzanie podobnych obliczeń z modyfikacją niektórych parametrów wskazane jest wykorzystanie środowiska obliczeń MES z możliwością zautomatyzowania obliczeń w pętli. Do celów niniejszego artykułu wykorzystano środowisko OpenSees [11], które oparte jest na języku programowania Tcl.

\section{Wyniki obliczeń}

Po wykonaniu obliczeń zgodnie z procedurą przedstawioną w poprzednim punkcie otrzymano wyniki zależności maksymalnego przemieszczenia $\mathrm{w}$ funkcji $t_{r}$ co pokazano na rys 4. Można zauważyć, że największe maksymalne przemieszczenia występują dla $t_{r}=0,001$, czyli równego krokowi czasowemu $\Delta t$, a następnie wartości spadają, by ustabilizować się na poziomie przemieszczenia, które wynika ze quasi-statycznego monotonicznego usuwania słupa, co oznaczone jest po prawej stronie osi wykresów jako wartość 1,0. Tym samym można zaobserwować jako rośnie współczynnik dynamiczny dla krótszych czasów trwania $t_{r}$. Dla $t_{r}=0,001$, wartości współczynników dynamicznych wynoszą odpowiednio: A) 2,91 ; B) 2,24; C) 1,87; dla trzech scenariuszy utraty słupa. 

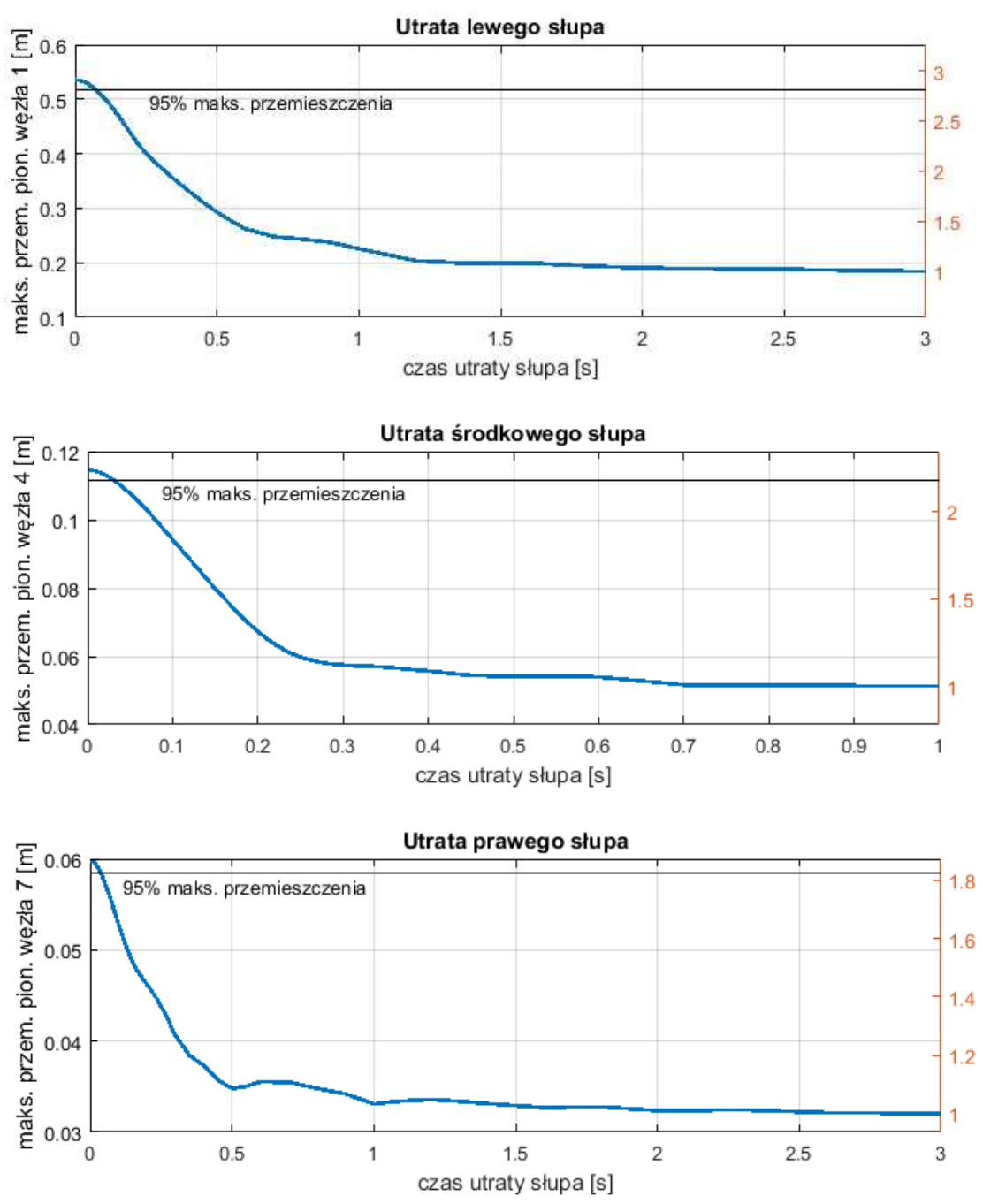

Rys. 4. Zależność czasu utraty słupa względem maksymalnego przemieszczenia w kierunku pionowym w węźle pod którym słup uległ zniszczeniu: a) utrata słupa A, b) utrata słupa B c) utrata słupa C

Fig. 4. Relationship between the time of column removal and maximum vertical displacement at node under which the column has been destroyed: a) removal of column A, b) removal of column B, c) removal of column $\mathrm{C}$

Wartości czasu trwania utraty słupa, dla których amplituda odpowiedzi spada poniżej umownego poziomu 95\% maksymalnego możliwego przemieszczenia dla najmniejszego czasu trwania utraty słupa $(0,001 \mathrm{~s})$, wynoszą odpowiednio dla poszczególnych scenariuszy: A) $0,073 \mathrm{~s}, \mathrm{~B}$ ) $0,031 \mathrm{~s}, \mathrm{C}$ ) 0,038 s (co pokazano na rys. 4). Jeśli odniesie się je do wartości okresów drgań własnych 
( $\mathrm{T}_{2} \mathrm{z}$ tabeli 1) to znormalizowane wartości wynoszą odpowiednio: A) 0,39, B) 0,25 , C) 0,33 . Można zauważyć, że im ten okres jest krótszy tym szybciej konstrukcja reaguje na nagłą utratę elementu podpierającego. Intuicyjnie można by postawić hipotezę (zwłaszcza dla analizy liniowo-sprężystej), że wpływ czasu trwania utraty słupa na dynamiczną odpowiedź konstrukcji związany jest z okresem drgań własnym odpowiadającym postaci (niekoniecznie pierwszej postaci drgań wynikającej z rozwiązania zagadnienia własnego), która przedstawia ruch w kierunku pionowym konstrukcji bez słupa, jednak fakt, że podczas utraty słupa następuje uplastycznienie w najbardziej wytężonych przekrojach, co z kolei pociąga za sobą zmniejszenie sztywności (zwiększenie okresów drgań), dlatego potwierdzenie postawionej hipotezy nie jest oczywiste.

Na rys. 5 przedstawione są wybrane przebiegi czasowe przemieszczeń pionowych w węzłach 1,4 i 7 zgodnie $z$ rys. 1 scenariuszy utraty słupa. Warto zauważyć, że dla scenariusza A) i B) dominuje jedna postać drgań własnych, natomiast dla scenariusza $C$ ) widoczne są drgania, gdzie dominujące są dwie postacie drgań własnych, co powoduje, że maksymalna wartość przemieszczenia pionowego jest mniej przewidywalna dla ustalonego $t_{r}$ i w związku z tym wykres na rys. 4C nie jest monotonicznie malejący (pojawiają się minima lokalne). Ponadto na rys. 5 widoczne są drgania oscylujące wokół docelowego przemieszczenia z okresem drgań własnych odpowiadającym wartościom z tabeli 1, wartość oznaczona symbolem "*". Oznacza to, że w pierwszej fazie po utracie słupa następuje ruch konstrukcji w dół i jeśli w pozostałej części konstrukcji zdoła wykształcić się zastępcza ścieżka obciążenia (dzięki dyssypacji energii i uplastycznieniu materiału w najbardziej wytężonych przekrojach), wówczas sztywność konstrukcji jest mniejsza i tym samym wydłużają się okresy drgań własnych.

\section{Podsumowanie i wnioski}

W niniejszym artykule przedstawiono procedurę i wyniki, których zadaniem było określenie wpływu szybkości utraty słupa na efekty dynamiczne w odpowiedzi konstrukcji. Obciążenie wyjątkowe jakim jest np. eksplozja ładunku wybuchowego może spowodować zniszczenie elementu nośnego w ciągu kilku milisekund, zatem celowe jest zbadanie jaki przyjąć krok czasowy, aby osiągnąć kompromis między dokładnością wyników i zminimalizować czasochłonność obliczeń. 

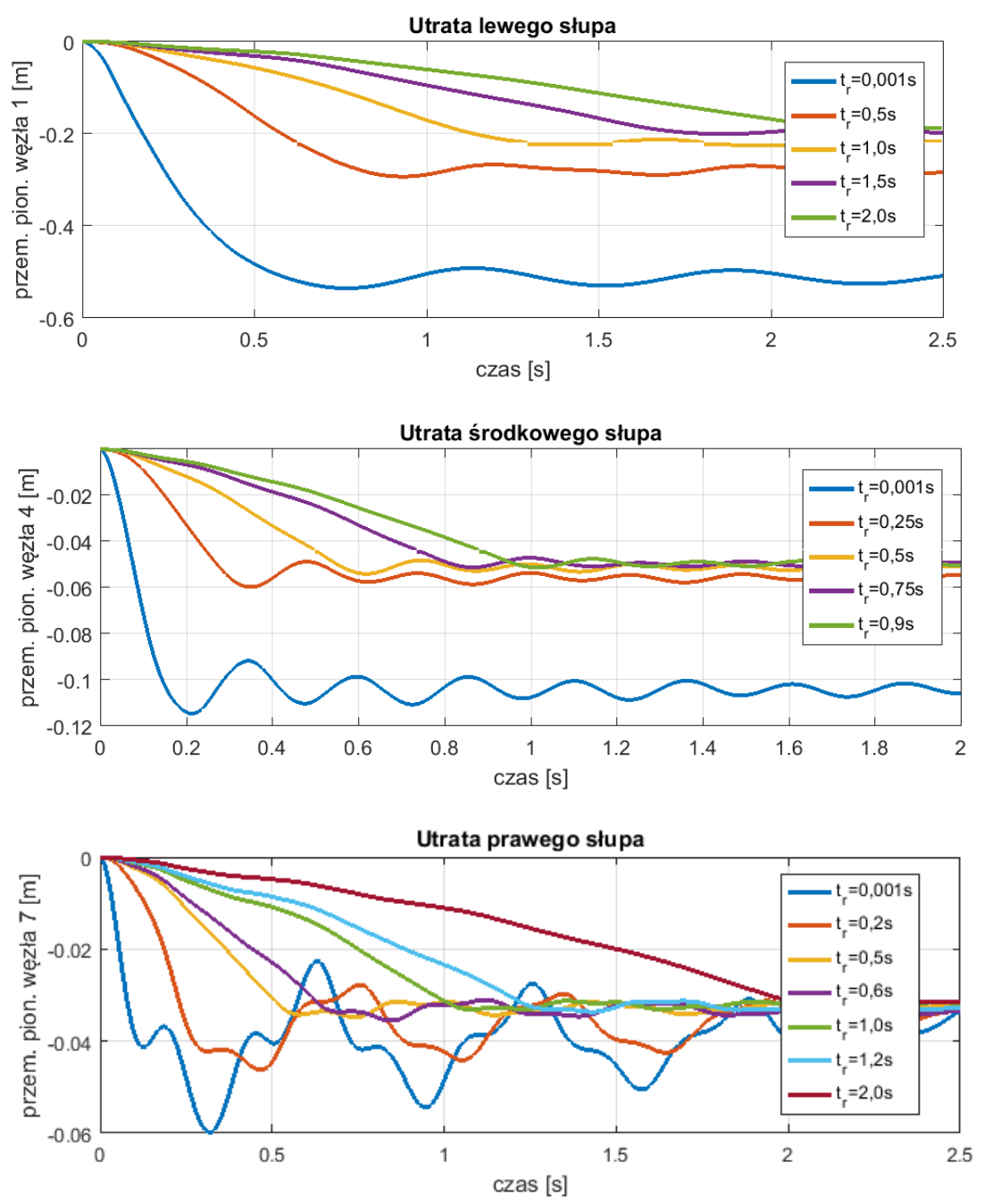

Rys. 5. Przebiegi czasowe przemieszczeń pionowych w węźle, pod którym słup uległ zniszczeniu dla wybranych czasów trwania utraty słupa dla przypadków A, B i C

Fig. 5. Time histories of vertical displacement at node under which the column has been destroyed for selected time duration of column removal for cases A, B and C

Na podstawie wyników otrzymanych dla konkretnej konstrukcji żelbetowej z trzema przypadkami utraty pojedynczego słupa, można sformułować następujące wnioski:

- maksymalne pionowe przemieszczenie w węźle nad usuniętym słupem przy najmniejszym czasie utraty słupa $(0,001 \mathrm{~s})$ jest $2-3$ krotnie większe od analogicznego przemieszczenia przy prawie-statycznej utracie słupa (długi czas usuwania reakcji pochodzących od podpierającego słupa), 
- czasy trwania utraty słupa powodujący przemieszczenia pionowe na umownym poziomie $95 \%$ maksymalnego możliwego przemieszczenia pionowego $\left(\right.$ dla $\left.t_{r}=0,001 \mathrm{~s}\right)$ są rzędu 0,03-0,07 s (rys. 4), co oznacza, że zarówno krok czasowy jak i czas utraty słupa może wynosić maksymalnie 0,01s. Przy czym, krótsze chwile czasowe wymagane są w pierwszej fazie (do maksymalnego przemieszczenia pionowego), a dłuższe chwile czasowe można przyjąć w drugiej fazie, co preferuje użycie metody całkowania numerycznego równań ruchu, w której krok czasowy jest przyjmowany w sposób zmienny. Z drugiej jednak strony obliczenia nieliniowe mogą wymagać krótszych chwil czasowych niezbędnych do osiągnięcia zbieżności obliczeń np. w metodzie Newtona-Raphsona,

- rozwiązanie zagadnienia własnego wskazuje, że pierwsza postać drgań to drgania w kierunku poziomym, a w drugiej postaci dominuje ruch konstrukcji w kierunku pionowym. Ta druga postać dominuje $\mathrm{w}$ drganiach konstrukcji po utracie słupa w przypadku A i B (rys. 5A i B), natomiast w przypadku C, dodatkowo widoczny jest udział kolejnej postaci opisującej ruch w kierunku pionowym (rys 5C). Dla analizowanej konstrukcji przed uplastycznieniem okresy drgań własnych $\mathrm{T}_{2}$ są w zakresie $0,11-0,19$ s (zob. tabela 1),

- fakt uplastycznienia niektórych przekrojów (przywęzłowych lub przęsłowych) powoduje zmniejszenie sztywności i tym samym wydłużenie okresów drgań własnych (tabela 1, wartości oznaczone symbolem "*"), a zatem najczęściej stosowana analiza liniowa (liniowość materiałowa) nie pozwalałaby na określenie zmian sztywności i tym samym prowadziłaby do innych wniosków.

\section{Literatura}

[1] DoD UFC Guidelines., Design of Buildings to Resist Progressive Collapse, Unified Facilities Criteria (UFC) 4-023-03. Department of Defence (DoD), 2005.

[2] PN-EN 1991-1-7, Eurokod 1 - PN-EN 1991-1-7: Oddziaływania na konstrukcje Część 1-7: Oddziaływania ogólne - Oddziaływania wyjątkowe, 2006.

[3] GSA Guidelines., GSA Progressive Collapse Analysis and Design Guidelines for New Federal Office Buildings and Major Modernizations Projects. General Services Administration (GSA), 2003.

[4] Kokot S.: Literature survey on current methodologies of assessment of building robustness and avoidance of progressive collapse. JRC Scientific and Technical Reports JRC 5598, European Commission, Joint Research Centre, 2009.

[5] Kokot S., Anthoine A., Negro P., Solomos G.: Static and dynamic analysis of a reinforced concrete flat slab frame building for progressive collapse. Engineering Structures, vol. 40, 2012, pp. 205-217.

[6] Kokot, S., Analiza ramy żelbetowej na obciążenia wyjątkowe według metody zastępczej ścieżki obciążenia, Inżynieria i Budownictwo, 8, 2012, pp. 444-446.

[7] Neuenhofer A., Filippou, F. C., Evaluation of nonlinear frame finite element models, Journal of Structural Engineering, vol. 123, 7, 1997, pp. 958-966. 
[8] Scott B. D., Park R., Priestley M. J. N., Stress-strain behavior of concrete confined by overlapping hoops at low and high strain rates, ACI Journal, 1982, vol = 79, 1, pp. 13-27.

[9] Filippou F. C., Popov E. P., Bertero V. V., Effects of bond deterioration on hysteretic behavior of reinforced concrete joints, University of California, Berkeley, 1983.

[10] Crisfield M., Nonlinear finite element analysis of solids and structures, Wiley, 1991, New York.

[11] McKenna F.,Fenves G. L., Scott M. H., OpenSees - Open system for earthquake engineering simulation, Pacific Earthquake Engineering Research Center, University of California, Berkeley, CA., http://opensees.berkeley.edu.

\section{DYNAMIC RESPONSE OF A REINFORCED CONCRETE STRUCTURE UNDER SUDDEN COLUMN REMOVAL}

\section{S u m m a r y}

In frame structures, a sudden column removal, which can be triggered by a blast of an explosive material or a vehicle impact, causes dynamic response, which in case of insufficient structural capacity can lead to partial or total progressive collapse. The notion of suddenness is imprecise and therefore it is worth to evaluate how the rate of column removal influences the maximum displacement and how this displacement refers to the displacement produced by static column removal. To this end, the response from numeric simulations of a reinforced concrete column-beam structure has been evaluated. This real structure had been earlier tested experimentally for quasistatic column removals. The numerical simulations consist in progressive increase of time of column removal from zero to the value, which asymptotically approaches the static response. Since the lengths of frame spans are not equal, three column removal scenarios have been investigated. It should be noted that the impact of rate of column removal depends on the ability of the remaining structure to withstand the lack of column and this reflects in the natural period for mode corresponding to the vertical downward motion of the model without the column. It is also interesting to compare the time duration of column removal for which the response is in the range of $95 \%$ of maximum dynamic response for three column removal scenarios and the normalized time related to the corresponding natural period. This indication can be useful when selecting the time step in numerical integration of equations of motion in dynamic analysis using finite element method.

Keywords: progressive collapse, accidental loading, modelling of reinforced concrete structures, dynamic factor

Przestano do redakcji: $15.02 .2017 \mathrm{r}$.

Przyjęto do druku: 28.04.2017 r. 